\title{
Tracing lineage by phenotypic and genotypic markers in Salmonella enterica subsp. enterica serovar 1,4,[5],12:i:- and Salmonella Typhimurium isolated in state of São Paulo, Brazil
}

\author{
Ana T Tavechio ${ }^{1 /+}$, Sueli A Fernandes ${ }^{1}$, Ângela CR Ghilardi ${ }^{1}$, Geoff Soule $^{2}$, Rafiq Ahmed ${ }^{2}$, \\ Carmo EA Melles ${ }^{1}$
}

'Laboratório de Bacteriologia/Enteropatógenos do Instituto Adolfo Lutz, Av. Dr. Arnaldo 355/9º 01246-902 São Paulo, SP, Brasil ${ }^{2}$ Enteric Disease Program, National Microbiology Laboratory, Health Canada, Winnipeg, Manitoba, Canada

Fifty-three Salmonella 1,4,[5],12:i:- and 45 Salmonella Typhimurium strains were characterised using phage typing, plasmid profiles and pulsed-field gel electrophoresis (PFGE) for comparison. The majority of the strains were subdivided into definitive type (DT) 41 (22.6\%) and DT 193 (18\%) and the 60-MDa plasmid was detected in 94.3\% and $84.4 \%$ of strains, respectively. Genetic diversity was observed among all strains and $90 \%$ presented a $>70 \%$ similarity through PFGE analysis. These results suggest a close relationship between Salmonella 1,4,[5],12:i:- and Salmonella Typhimurium at the serotype level.

Key words: Salmonella phage typing - plasmids - pulsed-field gel electrophoresis

Salmonellosis has been a public health concern in the world due to the zoonotic feature of most Salmonella serovars. The laboratory surveillance of salmonellosis by serotyping has taken place at the Adolfo Lutz Institute in state of São Paulo (SP), Brazil since the 1940s (Taunay et al. 1996, Tavechio et al. 1996, 2002, Fernandes et al. 2006). A five-fold increase of Salmonella enterica subsp. enterica serovar 1,4,[5],12:i:- was observed in the 1990s (Tavechio et al. 2004) since its initial isolation in the late 1970s (Calzada et al. 1984). It has been among the top five Salmonella serovars that have been isolated from human and non-human sources associated with foodborne outbreaks in human and extra-intestinal infections. This monophasic serovar has also been detected in several other countries and it is hypothesised that it could be Salmonella Typhimurium with an antigenic formula $(1,4,[5], 12: \mathrm{i}: 1,2)$, serovar Lagos $(1,4,[5], 12: \mathrm{i}: 1,5)$ without the second-phase $\mathrm{H}$ antigen (Popoff 2001), or possibly a new monophasic Salmonella serovar according to the review reported by Switt et al. (2009). This study was designed to use phenotypic and genotypic markers to compare Salmonella 1,4,[5],12:i:- and Salmonella Typhimurium strains from human and nonhuman sources from SP, from 1991-2000, to determine the lineage of these two salmonella groups.

Fifty-three Salmonella 1,4,[5],12:i:- strains, which were previously analysed by antimicrobial susceptibility testing (susceptible and resistant to 1-13 antimicrobials)

Financial support: FOGARTY International Center, National Institute of Health (D43 TW006592)

+ Corresponding author: atavechio@ial.sp.gov.br

Received 26 February 2009

Accepted 29 September 2009 and confirmed as $f l j B$-negative (Tavechio et al. 2004), were included in this study. These strains were mostly from human sporadic cases, intestinal $(n=23)$ and extra-intestinal $(\mathrm{n}=19)$ infections and non-human sources, such as laboratory animals $(n=6)$, meat $(n=3)$, dessert $(\mathrm{n}=1)$ and environment $(\mathrm{n}=1)$ from various geographic areas in SP from 1991-2000. Forty-five Salmonella Typhimurium strains (susceptible or resistant to two-seven antimicrobials, which were isolated from 1991-2000, were selected from a previous study (Ghilardi et al. 2006) and included in this study for comparison.

Phage typing was performed using the specific Salmonella Typhimurium phage-typing scheme (Anderson et al. 1977) at the Enteric Disease Program, National Microbiology Laboratory, Public Health Agency of Canada in Winnipeg, Manitoba, Canada. All strains were typeable and the lytic patterns not conforming to standard patterns were assigned as atypical (AT) or reaction does not conform (RDNC).

The distribution of phage types of Salmonella Typhimurium and Salmonella 1,4,[5],12:i:- strains is shown in Table. According to the number of Salmonella Typhimurium included in this study, the two most prevalent phage types were AT 04-2406 (24.5\%) and definitive type (DT) 193 (18\%), whereas for Salmonella 1,4,[5],12:1:- phage type DT41 was the prevailing one accounted for $22.6 \%$ of the strains and was followed by AT 00-0677 (13.2\%). By comparing the results from both groups described herein, it was verified that 11 Salmonella Typhimurium strains shared four common phage types (DT193, DT104b, DT120 and DTU302) with 19 Salmonella 1,4,[5],12:i:strains. Two strains from each group could not be typed by an initial phage typing scheme. These results showed that the great majority of Salmonella $\underline{1}, 4,[5], 12: 1:-$ strains were lysed by the phages composing the specific Salmonella Typhimurium phage typing scheme suggesting a close relationship between these two serotypes. 


\section{TABLE}

Relationship between phage type and pulsed-field gel electrophoresis (PFGE) profiles of Salmonella Typhimurium and Salmonella 1,4,[5],12:i:- strains isolated during 1991-2000, in state of São Paulo, Brazil

\begin{tabular}{|c|c|c|c|c|}
\hline \multirow[b]{2}{*}{ Phage type } & \multicolumn{2}{|r|}{ Salmonella Typhimurium $(\mathrm{n}=45)$} & \multicolumn{2}{|r|}{ Salmonella 1,4,[5],12:i:- $(\mathrm{n}=53)$} \\
\hline & $\begin{array}{c}\text { Strains } \\
(\%)\end{array}$ & PFGE profiles $^{a}$ & $\begin{array}{c}\text { Strains } \\
(\%)\end{array}$ & PFGE profiles $^{a}$ \\
\hline DT 4 & $1(2.2)$ & $\mathrm{Xt} 24$ & 0 & - \\
\hline DT 10 & $1(2.2)$ & $\mathrm{Xt10}$ & 0 & - \\
\hline DT 27 & $1(2.2)$ & Xt6 & 0 & - \\
\hline DT 49 & $6(13.4)$ & Xt1 (3), Xt20, Xt25, Xt28 & 0 & - \\
\hline DT 99 & $1(2.2)$ & Xt11 & 0 & - \\
\hline DT 104 & $1(2.2)$ & $\mathrm{Xt3}$ & 0 & - \\
\hline DT $110 b$ & $1(2.2)$ & Xt13 & 0 & - \\
\hline DT 135 & $2(4.5)$ & $\mathrm{Xt1}, \mathrm{Xt17}$ & 0 & - \\
\hline DT 153 & $1(2.2)$ & $\mathrm{Xt} 23$ & 0 & - \\
\hline AT 97-6274 & $1(2.2)$ & $\mathrm{Xt9}$ & 0 & - \\
\hline AT 97-6276 & $1(2.2)$ & $\mathrm{Xt8}$ & 0 & - \\
\hline AT 04-2406 & $11(24.5)$ & Xt1 (4), Xt7, Xt12, Xt14, Xt16, Xt18, Xt19, Xt26 & 0 & - \\
\hline AT $04-4538$ & $1(2.2)$ & $\mathrm{Xt} 21$ & 0 & - \\
\hline AT 04-6846 & $1(2.2)$ & $\mathrm{Xt15}$ & 0 & - \\
\hline AT 04-6871 & $1(2.2)$ & $\mathrm{Xt4}$ & 0 & - \\
\hline AT 04-6884 & $1(2.2)$ & $\mathrm{Xt4}$ & 0 & - \\
\hline UT 7 & $1(2.2)$ & Xt6 & 0 & - \\
\hline UT 8 & $1(2.2)$ & $\mathrm{Xt} 27$ & 0 & - \\
\hline DT $104 b$ & $1(2.2)$ & $\mathrm{Xt3}$ & $6(11.3)$ & X4 (3), X7 (2), X22 \\
\hline DT 120 & $1(2.2)$ & $\mathrm{Xt} 31$ & $5(9.5)$ & X2 (4), X30 \\
\hline DT 193 & $8(18.0)$ & $\mathrm{Xt} 2$ (3), Xt5 (2), Xt22, Xt29, Xt32 & $6(11.3)$ & X6 (2), X11, X23, X24, X27 \\
\hline DT U302 & $1(2.2)$ & $\mathrm{Xt} 30$ & $2(3.8)$ & X19, X29 \\
\hline DT 41 & 0 & - & $12(22.6)$ & X1 (6), X14, X15, X18, X20, X25, X26 \\
\hline DT 180 & 0 & - & $3(5.6)$ & $\mathrm{X} 2(2), \mathrm{X} 28$ \\
\hline DT 208 & 0 & - & $2(3.8)$ & X31, X32 \\
\hline AT 00-0677 & 0 & - & $7(13.2)$ & X3 (5), X16, X17 \\
\hline AT 04-6814 & 0 & - & $3(5.6)$ & X5 (2), X10 \\
\hline AT 04-6788 & 0 & - & $1(1.9)$ & X9 \\
\hline AT 04-6811 & 0 & - & $1(1.9)$ & $\mathrm{X} 21$ \\
\hline AT 00-3219 & 0 & - & $1(1.9)$ & $\mathrm{X} 13$ \\
\hline AT 04-6828 & 0 & - & $1(1.9)$ & X33 \\
\hline AT 04-6839 & 0 & - & $1(1.9)$ & $\mathrm{X} 12$ \\
\hline UT & 0 & - & $2(3.8)$ & $\mathrm{X} 8$ \\
\hline
\end{tabular}

$a$ : number of strains for PFGE profile; AT: atypical; DT: definitive type; UT: untypeable.

A previous study on phage typing, antimicrobial resistance and plasmidial profiles of Salmonella Typhimurium isolated from children living in two Brazilian cities, Salvador and Rio de Janeiro, was described by Asensi et al. (1995). They also detected the predominance of DT193 (47.7\%) among six different phage types as well as a significant percentage $(31 \%)$ of strains that could not be typed, with $2 \%$ considered to be RDNC. They did not detect any DT 104 isolate.

Five monophasic strains displaying resistance to ampicillin, chloramphenicol, streptomycin, sulphonamides and tetracycline (pentaresistant or R-type ACSSuT) belonged to
DT 193 (2), DT 208, DT 104b and DT U302. There were no monophasic strains phage typed as DT 104; however, one Salmonella Typhimurium DT 104 strain R-type ACSSuT was detected. Another seven Salmonella Typhimurium strains [phage types AT 04-2406 (3), AT 04-6846, DT 49, DT 135 and DT 104b] displayed the pentaresistant pattern. Although streptomycin was not included in the study reported by Asensi et al. (1995) in Brazil, they also found 47\% of Salmonella Typhimurium isolates with the ACSSuT pattern.

In Spain, Echeita et al. (1999) found that all $288 \mathrm{Sal}$ monella 4,5,12:i:- strains isolated from humans and pork products in 1998 and 1999, which were analysed by phage 
typing and antimicrobial susceptibility, belonged to phage type DT U302 and most of them presented R-type ACSSuT. Afterwards, de la Torre et al. (2003), also in Spain, compared 23 Salmonella 4,5,12:i:- to 24 Salmonella Typhimurium isolates from 1998-2000 by pulsed-field gel electrophoresis (PFGE) and plasmid profiling. These belonged to four and six phage type patterns respectively, with most of them being pentaresistant. The authors found subtypes that were closely related ( $>80 \%$ similarity) and possibly related $(>65 \%$ and $<80 \%$ similarity) and because $70 \%$ of the Salmonella 4,5,12:i:- isolates were phage type DT
U302, the authors suggested that those monophasic isolates originated from Salmonella Typhimurium DT U302.

In a recent study from Luxembourg, Mossong et al. (2007) reported the occurrence of outbreaks due to Salmonella 1,4,[5],12:i:- phage type DT 193 with the R-type ASSuT. The phage typing results of our monophasic strains showed that DT 193 ranked third (6 strains) along with DT 104b and included two pentaresistant (ACSSuT) strains with eight additional markers.

The plasmid profiles were determined using the alkaline extraction method for small volumes of cell cultures

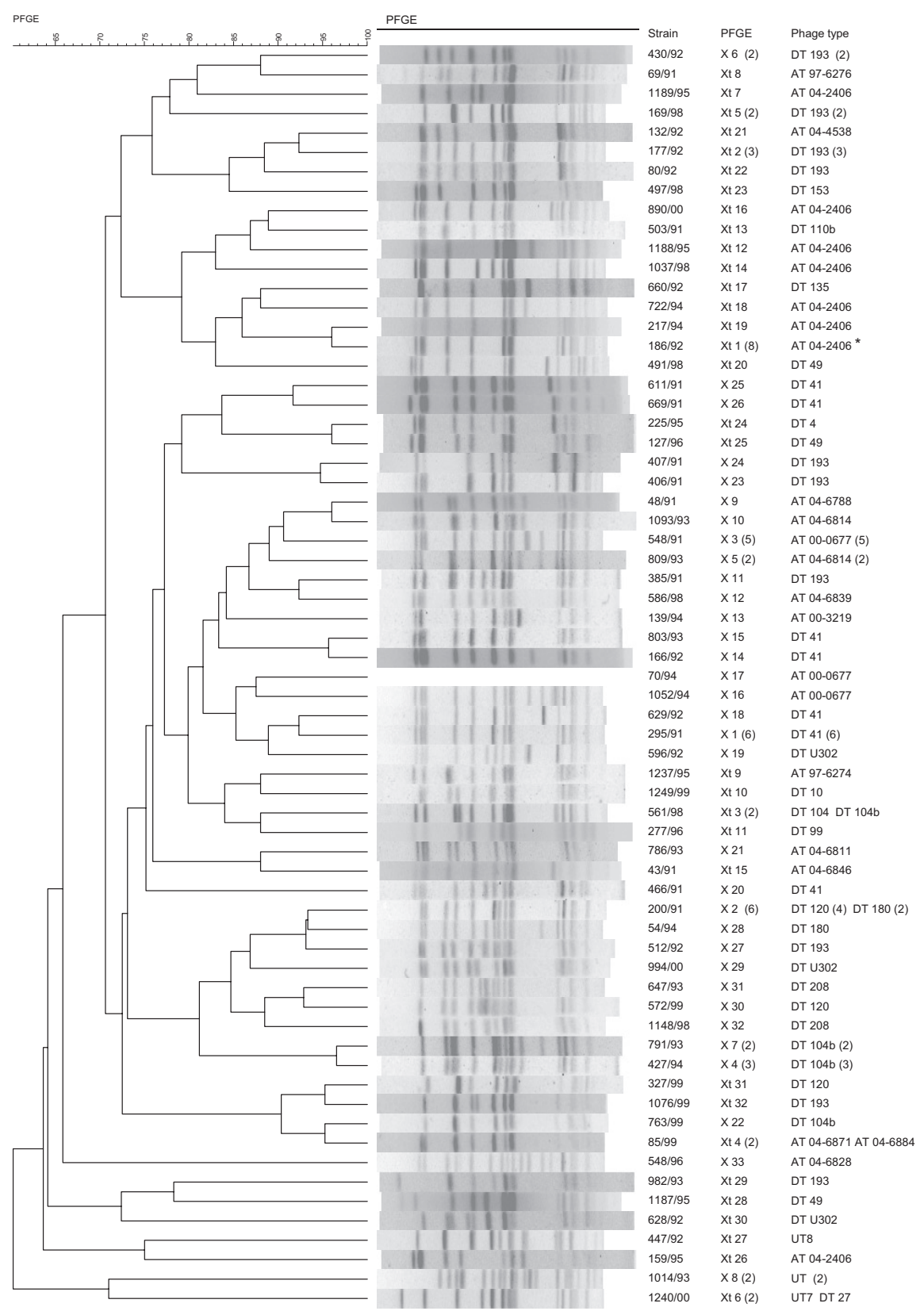

Fig. 1: dendrogram generated by BioNumerics software showing the relationship between Salmonella 1,4,[5],12:i:- (X) and Salmonella Typhimurium (Xt) serovars obtained by pulsed-field gel electrophoresis (PFGE) after XbaI restriction. Number of strains displaying each PFGE or phage type is between parenthesis. Assigned as atipical (AT) 04-2406 (4); definitive type (DT) 49 (3); DT 135 (1). 


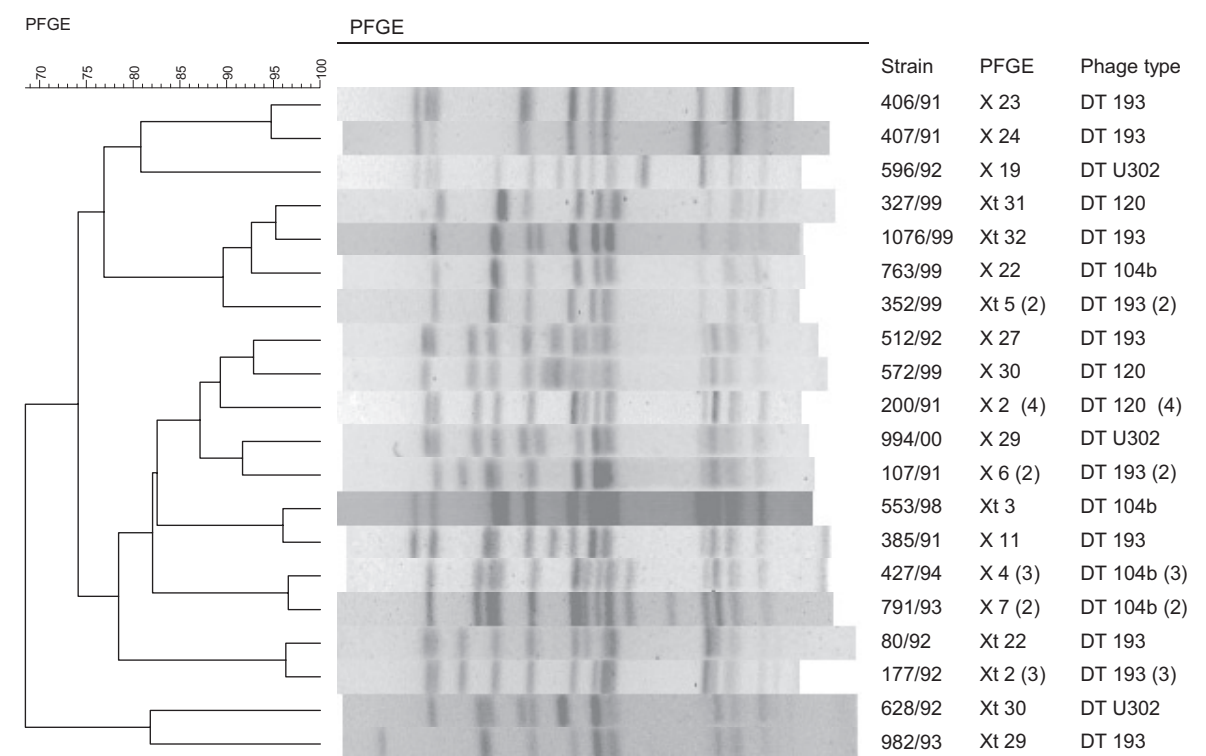

Fig. 2: dendrogram generated by BioNumerics software showing the relationship among strains belonging to the four phage types found in common with Salmonella 1,4,[5],12:i:- (X) and Salmonella Typhimurium (Xt) serovars, obtained by pulsed-field gel electrophoresis (PFGE) after XbaI restriction. Number of strains displaying each PFGE or phage type is between parenthesis. Dice (opt: $1.50 \%)($ tol: $1.5 \%-1.5 \%)(\mathrm{H}>0 \%$ $\mathrm{S}>0 \%)[0 \%-100 \%]$. DT: definitive type.

as described by Birnboim and Doly (1979). The approximate molecular masses of the plasmids are determined by comparing plasmids of known molecular mass.

Plasmid analysis detected 14 different profiles with 1-5 plasmids among the Salmonella 1,4,[5],12:i:- strains and the great majority of those $(94.3 \%)$ carried a 60 -MDa plasmid alone $(62.3 \%)$ or in combination with other plasmids of different sizes (32.1\%). Among the Salmonella Typhimurium strains, there were 10 different plasmid profiles with zero-4 plasmids and $38(84.4 \%)$ strains carried the 60-MDa plasmid alone or in combination with others of different sizes. In addition, the 60-MDa plasmid extracted from two Salmonella 1,4,[5],12:i:- and two Salmonella Typhimurium strains, which underwent plasmid restriction analysis with EcoRI and HindIII restriction enzymes, displayed the same restriction pattern. Asensi et al. (1995) reported that $41 \%$ of all Salmonella Typhimurium isolates analysed harboured a 61-MDa plasmid in a total of 33 different profiles. Because the $60-\mathrm{MDa}$ plasmid is known as the Salmonella Typhimurium serovar-associated plasmid (Helmuth et al. 1985), which is dominant in Salmonella Typhimurium strains (Liebana et al. 2002), our results suggest a close relationship between these monophasic strains and Salmonella Typhimurium.

PFGE analysis was performed according to the CDC PulseNet Protocols (CDC 2004) using a CHEF-DR II system (BioRad Laboratories, Hercules, California). An XbaI digestion of the $S$. Braenderup H9812 control strain (Hunter et al. 2005) was used for DNA size markers. The PFGE gel was stained with ethidium bromide and the gel image was captured on the GEL DOC EQ system (Quantity One version 4.5 - Universal Hood II, Bio-Rad Laboratories, Milan, Italy) and analysed with BioNumerics software version 5.0 for Windows (Applied Maths, Belgium) to generate a dendrogram. The dice coefficient ( $1.5 \%$ tolerance) and the unweighted pair group method using arithmetic averages were used to perform the clustering analysis. Each PFGE profile that differed at least by one fragment was assigned a type number with X1- $\mathrm{X}^{\mathrm{n}}$ for Salmonella $1,4,[5], 12: \mathrm{i}$ - and $\mathrm{Xt1}-\mathrm{Xt}^{\mathrm{n}}$ for Salmonella Typhimurium.

PFGE analysis generated 9-18 fragments, with sizes between $33.3-1,135 \mathrm{~kb}$ per strain. There were 33 different profiles (X1 - X33) detected among 53 Salmonella 1,4,[5],12:i:- and 32 (Xt1 - Xt32) among 45 Salmonella Typhimurium strains with X1, X2 (11.3\%) and Xt1 (18\%) as the most prevalent profiles, respectively. A dendrogram combining the two serovar genetic profiles resulted in 65 different PFGE profiles and most of these (90\%) showed similarity above $70 \%$ (Fig. 1). The distribution of PFGE profiles in relation to the phage types is shown in Table. Fig. 2 shows the relationship among the strains belonging to the four phage types found in common with Salmonella Typhimurium and Salmonella 1,4,[5],12:i:-.

It has been demonstrated that PFGE analysis can separate different Salmonella serotypes into distinct clusters (Liebana et al. 2001, Peters et al. 2003), also known as an inter-serotype discrimination. For strains belonging to one particular serotype, PFGE discriminates the ones associated with foodborne outbreaks from the ones isolated from sporadic cases of intestinal or extraintestinal infections denoting intra-serotype discrimination (Bender et al. 2001). The results obtained in this study showed a genetic diversity among all studied strains because they were isolated in a 10-year period and they were not associated with foodborne outbreaks. Besides, Salmonella Typhimurium and Salmonella 1,4,5,12:i:strains were distributed in high similarity PFGE clusters, suggesting a close relationship at the serotype level. 
Other studies describing the genetic similarity among strains from these two serotypes have been recently reported in Thailand (Pornruangwong et al. 2008), showing a close clonal relationship ( $\geq 85 \%$ similarity) by PFGE between the studied isolates and in the USA (Zamperini et al. 2007), where the results led to the conclusion that monophasic Salmonella 4,5,12:i:isolates are genotypically Salmonella Typhimurium and should be treated in the same way as this serotype, concerning to export or import restrictions of poultry with Salmonella Typhimurium.

In conclusion, the results obtained in this study suggest a close relationship between Salmonella 4,5,12:i:and Salmonella Typhimurium, although further genetic characterisation should be done in order to better trace the origin of the monophasic strains.

\section{ACKNOWLEDGMENTS}

To the staff of the Global Infectious Diseases Research Training Program (GIDRTP), Pittsburgh, USA, and of the Pitt/IAL GIDRTP Training Advisory Group whom kindly approved a training on Salmonella Typhimurium phage typing at the National Microbiology Laboratory in Winnipeg, Canada, to Tavechio.

\section{REFERENCES}

Anderson ES, Ward LR, De Saxe MJ, De As JDH 1977. Bacteriophage-typing designations of Salmonella Typhimurium. J Hyg Camb 78: 297-300.

Asensi MD, Costa AP, Reis EMF, Hofer E 1995. Lysotypes and plasmidial profile of Salmonella serovar Typhimurium isolated from children with enteric processes in the cities of Rio de Janeiro, RJ and Salvador, BA - Brazil. Rev Inst Med Trop Sao Paulo 37: 297-302.

Bender JB, Hedberg CW, Boxrud DJ, Besser JM, Wicklund JH, Smith KE, Osterholm MT 2001. Use of molecular subtyping in surveillance for Salmonella enterica serotype Typhimurium. $N$ Engl J Med 344: 189-195.

Birnboim HC, Doly J 1979. A rapid alcaline extraction procedure for screening recombinant plasmid DNA. Nucleic Acid Res 7: $1513-1523$.

Calzada CT, Neme SN, Irino K, Kano E, Dias AMG, Fernandes SA, Vaz TMI, Pessôa GVA 1984. Sorotipos de Salmonella identificados no período 1977-1982, no Instituto Adolfo Lutz, São Paulo, Brasil. Rev Inst Adolfo Lutz 44: 1-18.

CDC - Centers for Disease Control and Prevention 2004. PulseNet USA. One-day (24-48 h) standardized laboratory protocol for molecular subtyping of Escherichia coli O157: H7, non-typhoidal Salmonella serovars and Shigella sonnei by pulsed field gel electrophoresis (PFGE). Available from: http://www.cdc.gov/pulsenet.

de la Torre E, Zapata D, Tello M, Mejía W, Frías N, García Peña FJ, Mateu EM, Torre E 2003. Several Salmonella enterica subsp. enterica serovar 4,5,12:i:- phage types isolated from swine samples originate from serovar Typhimurium DT U302. J Clin Microbiol 41: 2395-2400.

Echeita MA, Aladueña A, Cruchaga S, Usera MA 1999. Emergence and spread of an atypical Salmonella enterica subsp. enterica serovar 4,5,12:i:- strain in Spain. J Clin Microbiol 37: 3425.

Fernandes SA, Tavechio AT, Ghilardi ACR, Dias AMG, Almeida IAZC, Melo LCV 2006. Salmonella serovars isolated from humans in São Paulo state, Brazil, 1996-2003. Rev Inst Med Trop Sao Paulo 48: 179-184.

Ghilardi ACR, Tavechio AT, Fernandes SA 2006. Antimicrobial susceptibility, phage types and pulsetypes of Salmonella Typhimurium strains, in São Paulo, Brazil. Mem Inst Oswaldo Cruz 101: 281-286.
Helmuth R, Stephan R, Bunge C, Hoog B, Steinbeck A, Bulling E 1985. Epidemiology of virulence-associated plasmids and outer membrane protein patterns within seven common Salmonella serovars. Infect Immun 48: 175-182.

Hunter SB, Vauterin P, Lambert-Fair MA, van Duyne MS, Kubota K, Graves L, Wrigley D, Barrett T, Ribot E 2005. Establishment of a universal size standard strain for use with the PulseNet standardized pulsed-field gel electrophoresis protocols: converting the national databases to the new size standard. J Clin Microbiol 43: $1045-1050$

Liebana E, Garcia-Migura L, Clouting C, Clifton-Hadley FA, Lindsay E, Threlfall EJ, McDowell SWJ, Davies RH 2002. Multiple genetic typing of Salmonella enterica serovar Typhimurium isolates of different phage types (DT104, U302, DT204b and DT49) from animals and humans in England, Wales and Northern Ireland. J Clin Microbiol 40: 4450-4456.

Liebana E, Guns D, Garcia-Migura L, Woodward MJ, Clifton-Hadley FA, Davies RH 2001. Molecular typing of Salmonella serotypes prevalent in animals in England: assessment of methodology. J Clin Microbiol 39: 3609-3616.

Mossong J, Marques P, Ragimbeau C, Huberty-Krau P, Losch S, Meyer G, Moris G, Strottner C, Rabsch W, Schneider F 2007. Outbreaks of monophasic Salmonella enterica serovar 4,[5],12:i:in Luxembourg, 2006. Euro Surveill 12: 156-158.

Peters TM, Maguire C, Threlfall EJ, Fisher IST, Gill N, Gatto AJ, on behalf of the Salm-gene project participants 2003. The Salm-gene Project - a European collaboration for DNA fingerprinting for food-related salmonellosis. Euro Surveill 8: 46-50.

Popoff MY 2001. Formules antigéniques des sérovars de Salmonella. Centre Collaborateur OMS de Référence et de Recherche pour les Salmonella, 8th ed., Institut Pasteur, Paris, 150 pp.

Pornruangwong S, Srlyapai T, Pulsrikarn C, Sawanpanyalert P, Boonmar S, Bangtrakulnonth A 2008. The epidemiological relationship between Salmonella enterica serovar Typhimurium and Salmonella enterica serovar 4,[5],12:i:- isolates from humans and swine in Thailand. Southeast Asian J Trop Med Public Health 39: 288-296.

Switt AIM, Soyer Y, Warnick LD, Wiedmann M 2009. Emergence, distribution and molecular and phenotypic characteristics of Salmonella enterica serotype 4,5,12:i:-. Foodborne Pathog Dis 6: 407-415.

Taunay AE, Fernandes SA, Tavechio AT, Neves BC, Dias AMG, Irino $\mathrm{K}$ 1996. The role of public health laboratory in the problem of salmonellosis in São Paulo, Brazil. Rev Inst Med Trop Sao Paulo 38: 119-127.

Tavechio AT, Fernandes SA, Neves BC, Dias AMG, Irino K 1996. Changing patterns of Salmonella serovars: increase of Salmonella enteritidis in São Paulo, Brazil. Rev Inst Med Trop São Paulo 38: 315-322.

Tavechio AT, Ghilardi ACR, Fernandes SA 2004. "Multiplex PCR" identification of the atypical and monophasic Salmonella enterica subsp. enterica serovar 1,4,[5],12:i:- in São Paulo state, Brazil: frequency and antibiotic resistance patterns. Rev Inst Med Trop Sao Paulo 46: 115-117.

Tavechio AT, Ghilardi ACR, Peresi JTM, Fuzihara TO, Yonamine EK, Jakabi M, Fernandes SA 2002. Salmonella serovars isolated from nonhuman sources in São Paulo, Brazil, from 1996 through 2000. J Food Prot 65: 1041-1044.

Zamperini K, Soni V, Waltman D, Sanchez S, Theriault EC, Bray J, Maurer JJ 2007. Molecular characterization reveals Salmonella enterica serovar 4,[5],12:i:- from poultry is a variant Typhimurium serovar. Avian Dis 51: 958-964. 